\title{
Quantifying the level of Emotional intelligence and Self Efficacy
}

\author{
MUHAMMAD TUFAIL \\ PhD Scholar, Riphah International University, Islamabad \\ tuphail@yahoo.com \\ MUHAMMAD BILAL \\ Abdul Wali Khan University Mardan \\ MUHAMMAD HAROON UR RASHID \\ Demonstrator, Institute of Business Studies and Leadership \\ Abdul Wali Khan University Mardan \\ DR. AAMIR ISHAQUE \\ Assistant professor, National University of Modern Languages, \\ Peshawar Campus
}

\begin{abstract}
Considering the increasing no of universities, the present study was carried out to quantify the level of emotional intelligence and self efficacy. Data was collected via wellestablished questionnaire from 96 faculty members of both Public and private sector universities located in Khyber Pukhtoonkhwa. Results indicate the difference of emotional intelligence and self efficacy in both the sector.
\end{abstract}

Key words: Emotional Intelligence, Self Efficacy

\section{Introduction}

Higher Education is normally found into highly specialized area of knowledge and traditional discipline. Learning is shattered and the professional often are discouraged to extend their work into other fields of study. Higher Education carries deep and high responsibility to enhance awareness, knowledge and skills required to support future prosperity. It gives the competent people who can lead the society into significant growth. Higher education is free in developing new ideas, pass opinion on society and to settle down the disputes (Cortese, 2003).

Education system has got major changes in the last few decades, but if the attention to teacher's emotional health is ignored, it will be very difficult for them to show effective results (Jacobs, Kemp, \&Mitchell,2008).In the view of Kyriacou (2000) teachers are helpless to the stress than other professionals. Many studies like (van Dick \& Wanger, 2001; Kyriacou, 1998) regarding teacher's stress which are based on the primary work of Kyriacou and Sutcleffe (1978) have cleared its occurrence and its severity in education system in different perspectives. Different types of studies have been conducted to get to know the normal basis of stress in classrooms and schools, aiming to understand the way of coping with stress faced by teachers. According to the studies conducted by Dunham (1992) and Traverse \& Cooper (1996) so many sources of stress have been identified in this regard like misbehavior of students, ill setting of institutes 
setting and discipline, lack of motivation of the students, task ambiguity and conflict with the top management of the institutions and the criticism of the parents toward the teachers. Teachers do not react in the same way and they develop different psychological and mental symptoms to cope with stress (Dunham, 1992). Similarly Chan (2008) argued that researchers have identified that personality and personal traits as coping resources in the context of stress and suffering association. Much $\mathrm{f}$ the research studies focused on the favorable responsibility of self efficacy in different academic and educational background (Schunk \& Meece,2005; Ghanizadeh \& Moafian, 2011a). Research studies have concluded that emotional intelligence is linked with success and achievement in many areas like academic performance (Gil-Olarte, Palomera, \& Brackett, 2006) and efficient teaching (Ghanizadeh \& Moafian, 2010). Studies have portrayed the importance of emotional understanding of teachers' and self-belief on their capabilities to handle and normalize their emotions (Aultman, Williams-Johnson, \& Schutz, 2010; Gibbs, 2003). Further Bandura (1991) concluded that self efficacy beliefs control functioning through various procedures.

The vital contribution of the current study is to provide evidences from a developing country Pakistan. In 2002 the government of Pakistan has established the Higher Education Commission in order to upgrade the education system in Pakistan. The commission is responsible to evaluate, promote and improve situation of Higher Education in Pakistan. According to education census (2005) the total number of colleges in the country is 1,882 , in which 1025 collages are in public sector and 857 in private sector. The total number of Universities is 114 in Pakistan. The number of Universities in Khyber-Pakhtunkhwa is 32 . After getting intermediate certificate only 3.5 percent of the enrolled students take admission in degree colleges, 0.6 take admission in general Universities and 1.08 get admissions in professional institutes (Educational Institutions Resources Bank, 2007). The environment, compensation and all other benefits are different across the universities, so it can be argued that the level of emotional intelligence and self efficacy will also be different among the both sectors. In order to carry out the comparative analysis, the present study has been conducted.

\section{Theoretical Background}

Emotions and social intelligence provided basis for the emotional intelligence which can be extracted from the work of Thorndike (1920). He further suggested that emotional intelligence is having three different aspects i.e. abstract intelligence which is the skills of an individual to understand the roots of idea, mechanical intelligence is related to the management of tangible objects and the last one is the social intelligence, related to the management of other individuals.

Salovey and Mayer (1990) for the first time defined that emotional intelligence is the division of social intelligence, which is the skills of the individuals to judge and manage own emotions, to distinguish and to act accordingly. With the gap of seven years and Mayer and Salovey (1997) reconceptualized the definition of emotional intelligence and stated that it is the capability to distinguish emotions, to make emotions, to understand, to adjust emotions due to the reason of increase in mental growth.

Various researchers like (Ciarrochi, Chan, \& Caputi, 2000; Goleman, 1995) studied and conceptualized emotional intelligence in different perspectives and this construct offer a good framework in a sense that provides the recognition and 
understanding of any kind of skill which is necessary to practice emotions in an adaptive manner. In the same vein Mayer and Salovey (1997) suggested that emotional intelligence can be conceptualized as the explicit and detailed ability in understanding emotions, help thoughts, awareness of emotions and to cope the emotions, The integrated process of emotional aptitudes might help in spotting teachers who are less exposed to teacher's strains and controlling emotions. These teachers possessed high degree of emotional intelligence.

Teachers know how to respond to job stressors, they possess quality information and have a greater tendency to act well out of emotions; they use this information along with adaptive coping guide to deal with the stressful situation (Jennings \&Greenberg, 2009).According to Bandura (1997), self efficacy is the degree of capability that an individual anticipates and behave in any situation. Considering the self efficacy of teachers (Gibbs \& Powell, 2012) suggested that it is the ability to sway the expected outcomes associated with students' performance. External and internal variables contribute to the teachers' self efficacy (Klassen, Tze, Betts, \& Gordon, 2011). Teachers' perceptions regarding the regulation and control of their emotion and thoughts in perspective of students' learning are considered as internal influence, while external influence contributes the factors like number of students, teaching material, and classroom environment (Ho \& Hau, 2004).

To assist coping, self efficacy is considered a vital personal resource (Knoll, Rieckmann, \& Schwarzer, 2005). Self-efficacy refer to individual belief regarding their competence to manage new tasks or to cope with difficulties associated with tasks or to handle strains associated with stressful situation (Bandura, 1997).Individual who possessed high degree of self-efficacy are known for performing the most challenging task, by setting their aim high, investing persistent and high efforts and remain fully committed to achieve their goal, contrary to individual with low degree of self-efficacy (Luszczynska \& Schwarzer, 2005).In educational sector, teacher confront more demanding jobs and strains related to this job , teachers with high degree of self-efficacy also confront these difficulties but they perceive these stressors to be more a challenge than a hindrance, therefore their high degree of self-efficacy helps them in coping the negative emotions associated with stressful situations. Contrast to these teachers, teachers with low degree of self-efficacy encounter more psychological distress in form of high self-doubts, anxiety and frustrations in stressful situations (Schwarzer \& Greenglass, 1999).

When evaluating self-efficacy, it appears more suitable to believe task-specific or domain specific self-efficacy,elaborates that teachers may not be able to behave efficiently in all areas of teachers' performance (Schwarzer \& Jerusalem, 1995).Studies also suggested that substantial changes in self-efficacy of teachers occur at slow phase, in parts due to variation in their emotions(Sutton and Wheatley, 2003).It has also been found that self-efficacy beliefs are anticipated significantly by emotional intelligence components and was suggested that this relationship is significantly affected by dissimilarity among teachers(Chan, 2004). Although few evidences are available on selfefficacy, among these studies emotions are considered as a major consequence of selfefficacy rather than as a predictor of individual efficacy beliefs (Sutton \& Wheatley, 2003). 
Efficacy beliefs are outcomes of cognitive process in which information from various sources are processed (Bandura, 1997), this type of state is known as Somantic and Emotional state, in this state emotional and physiological states conveyed the somatic information, in short it is basically individual perception of their own psychological and emotional position. Teachers own Emotional intelligence is reflected in a degree to which they are not only capable of managing their own emotion but can also handle other's emotions effectively (Atkins \& Stough, 2005).Chan (2004)suggested that inter personal intelligence anticipates teachers" self efficacy to help others. Likewise, it has also been found that emotional intelligence is directly lined with self efficacy(Penrose, Perry, and Ball (2007).In this regard Gibbs (2003) suggested that among teachers the actual teaching and self-efficacy beliefs are affected by their sense of control and by their faiths in themselves that they are capable of controlling their feelings and their thoughts. High degree of self efficacy in teaching will be observed by teachers' ability to recognize their emotions and to control them (Jennings\& Greenberg, 2009).

\section{Sampling and Data Collection Procedure}

All the universities of KP were the target population of the current study. The population was divided in two groups i.e. Public sector universities and Private sector universities. Faculty members from both sectors were selected randomly. The total no of universities in KP is 32 that encircles 21 in Public sector and 11 in Private sector. Only those universities were focused for data collection where management sciences department is established. Well established questionnaires were used to record the perception of employees regarding the variable used in this study. For this study, lecturers, assistant professors, associate professors and professors from both public and private sector universities were selected. In some universities demonstrator are also part of teaching but all the universities do not have this position so the demonstrators were not included in this study. Questionnaires were emailed to the selected faculty members and were requested to participate. A cover letter was also attached with self-reported questionnaire to informed respondent about the purpose of this study and to let them know that the data obtained from them will be kept strictly confidential.

In order to collect data from faculty members, 137 questionnaires were distributed among the faculty members of both public and private sector universities. We received 102 questionnaires yielding response rate of $74 \%$. The high response rate in Pakistan is high (Abbas, Raja, Darr, \& Bouckenooghe, 2014; Tufail, Gul, Shahzad, \& Khan, 2017). 48 questionnaires were received in complete form Public sector universities and were useable for analysis. In order to use same number of respondents 6 questionnaires (from private sector) was dropped randomly and96questionnaires were used for analysis.

\subsection{Measures}

All the measures for this study were adopted from previous studies and original English language self reported questionnaires were used. The medium of instruction in universities and means of communication in organizations is English although English is not the native language of Pakistan (Raja, Johns, \& Ntalianis, 2004), so there was no need to translate the questionnaire in native language. We recorded responses for all 
items on a 5 point Likert scale ranging from $1=$ strongly disagree, $2=$ disagree, $3=$ neutral, $4=$ agree to $5=$ strongly agree. The details of measures are as follows

\subsection{Emotional Intelligence}

To measure the emotional intelligence of teacher the instrument developed byPetrides \& Furnham (2006), and the cronbach alpha was found (0.78).

\subsection{Self Efficacy}

To measure the self efficacy the instrument developed by Gibson \& Demo (1984), and the cronbach alpha for the current study was found (0.71).

\section{Results}

\subsection{Descriptive Statistics}

Descriptive statistics shows that the minimum age of the respondent was 22 years and the maximum was 40 years. The mean values for age and standard deviation was 31.16 years and 0.36 respectively. As per rules the minimum qualification for teaching in university is master degree so the minimum level of education was kept to master degree holders. In case of qualification below 10 percent of the respondents were having the master degree, almost 83 percent of the respondents were having MS/MPhil degree and only 7 percent of respondents were having $\mathrm{PhD}$ degree. While asking about the experience it was found that the experience ranged from 1 year to 10 years, resulted the mean value of 2.11. The value of standard deviation for the experience in current school was 0.71 . Respondents having minimum experience were only 19 percent and more respondents were having 5 to 10 years of teaching experience.

Moreover, It is clear from the table given below that there is significant positive relation between emotional intelligence and self efficacy $(r=0.32$, where $p<0.01)$.

Table 1.Mean, Standard Deviation, Correlation and Reliabilities

\begin{tabular}{llccccccc}
\hline & & Mean & SD & 1 & 2 & 3 & 4 & 5 \\
\hline 1 & Age & 31.21 & 0.36 & - & & & & \\
2 & Experience & 2.05 & 0.71 & $0.42^{* *}$ & - & & & \\
3 & Qualificatio & 2.11 & 0.67 & $0.31^{* *}$ & 0.022 & - & & \\
& n & & & & & & & \\
4 & Emotional & 2.21 & 0.51 & $0.36^{* *}$ & $.024^{* *}$ & $0.38^{* *}$ & $(0.78)$ & \\
& Intelligence & & & $0.29 *$ & $.030^{* *}$ & $0.27^{* *}$ & $0.44^{* *}$ & $(0.71)$ \\
5 & Self Efficacy & 3.65 & 0.69 & $*$ & $.037^{*}$ & & & \\
\hline
\end{tabular}

$\mathrm{N}=96$; Cronbach's Alpha presented in parenthesis

**. Correlation is significant at the 0.01 level (2-tailed).

*. Correlation is significant at the 0.05 level (2-tailed).

It is clear from the table given below that the $\mathrm{p}$ value is less than the significant value $(p=0.05)$, for both self-efficacy $(p=0.03)$ and emotional intelligence $(p=0.02)$ supporting that there is difference between the level of that self-efficacy and emotional intelligence among faculty members of Public and Private sector universities. Also the result shows that for both variables the mean value is high in private sector universities than Public sector universities. 
Table 2. Mann-Whitney U Test

\begin{tabular}{cccccc}
\hline & Universities & $\mathrm{N}$ & Mean Rank & $\begin{array}{c}\text { Mann Whitney- } \\
\text { U Test }\end{array}$ & sig \\
\hline \multirow{2}{*}{ Self-efficacy } & Public & 48 & 40.14 & 719.0 & .003 \\
& Private & 48 & 56.86 & & \\
\hline $\begin{array}{c}\text { Emotional } \\
\text { intelligence }\end{array}$ & Public & 48 & 39.48 & 750.5 & .002 \\
\hline
\end{tabular}

\subsection{Cross Tabulation}

It is appropriate for summarization of categorical available to use cross tabulation technique .For current study to compare emotional intelligence and self-efficacy and among Government, Private and International schools cross tabulation was used. Instead of theoretical scores $(5 \times 20=100)$ and low score $(1 \times 20=20)$ the observed scores were utilized.Table 3 given below exhibits the level of self efficacy and emotional intelligence in both Public and Private sector Universities. The responses of respondents were calculated in the table No 3 given below. It is clear that the level of self efficacy is low in Private sector universities than in Public sector in two categories (low, Medium). Almost similar results can be found in case of emotional intelligence which makes clear that the level of emotional intelligence of Private sector universities is low in low and medium category while in high category it is more than in Private sector universities. Overall the results indicate that the level of self efficacy and emotional intelligence is high in Public sector universities.

Table 3. Sector wise Cross Tabulation

\begin{tabular}{llccc}
\hline & Sectors & Low & Medium & High \\
\hline \multirow{2}{*}{ Self-efficacy } & Public Universities & 15 & 24 & 9 \\
& Private Universities & 13 & 15 & 20 \\
\hline $\begin{array}{l}\text { Emotional } \\
\text { intelligence }\end{array}$ & Public Universities & 18 & 19 & 11 \\
& Private Universities & 10 & 16 & 22 \\
\hline
\end{tabular}

The graph illustrates that more respondents reported medium level of self efficacy in Public sector universities while respondents having low level of self efficacy were more in number in private sector universities than public sector. In case of emotional intelligence, the medium level of emotional intelligence was reported by more respondents in public sector universities than private sector while high level of emotional intelligence was observed in private sector universities. 
Figure 1. Comparative analysis of self efficacy and emotional intelligence across the sectors.

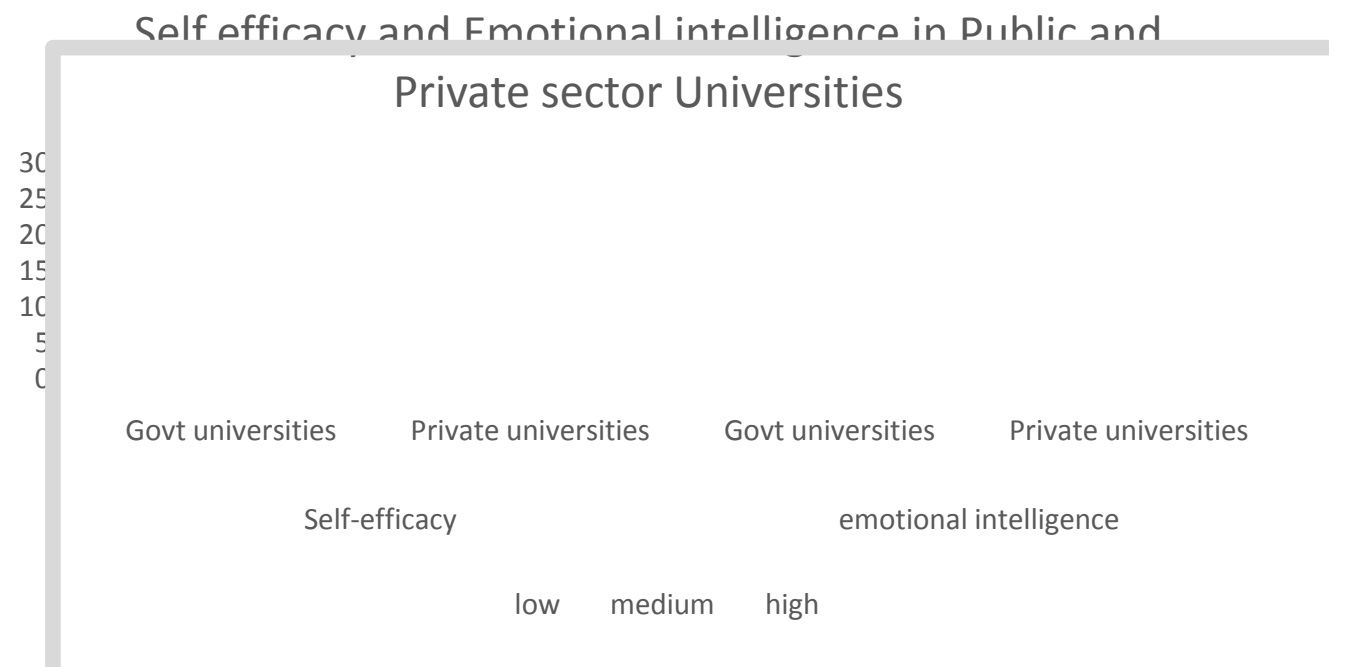

\section{Discussion}

The current study was conducted to compare Emotional Intelligence and selfefficacy beliefs between Public and private sector universities located in KP. Outcome of current research suggests that there is positive association between emotional intelligence and self-efficacy. The current results are in line with research conducted by Moafian and Ghanizadeh (2009) and Rastegar and Memarpour (2009).Moreover, Penrose et al. (2007) and Chan (2004) research studies based on secondary and primary schools also showed a positive association between EF and EI. The outcome illustrated through graphs and responses categorized into high, medium and low is based on study of Zia and Tufail (2011), that was on the faculty members of public and private sector universities in KP, where organizational commitment war illustrated through graph and responses were categorized in high medium and low, same techniques has been employed for this research.

Previously research studies have demonstrated that efficacy is related to important outcomes and little work has looked at the ability to influence teachers' efficacy (Fives, 2003). Teaching staff with high level of self-efficacy are found to develop student learning skills, behavior skills, and management skills at institutions (Chase, Lirgg, \& Carson, 2001).Studies have elaborated that efficacious teachers' students always perform better that than other class students (Henson,2001). Teaching staff with high emotional intelligence maintain a positive state of mind and with positive emotions and can generate more better ideas regarding teaching that make them able to juggle issues related to their profession (Frederickson, 2001).Future research can be carried out in different work environment. Work environments change the perception and way of dealing in organizations. So, it would be interesting to investigate that weather the emotional intelligence and self efficacy is based on individuals or working environment. While considering the leadership or management of the organization it has been found that ethical leadership plays a vital role in employees' behavior (Nuebern, 
Carlon.Kaemar, Roberts, \&Chonko, 2009). Hence, it is suggested that leadership gives future insights to be studied as moderator in relation between Emotional Intelligence and Self efficacy in same direction. Geher, Betancourt and Jewell (2017) found that the emotion detection ability is related to creativity when gender and age was controlled. This gives a clear direction that interesting results are expected if the age and gender is not controlled. Moreover, a comparative study is same direction can also be carried out between gender and different age groups.

\section{References}

Abbas, M., Raja, U., Darr, W., \& Bouckenooghe, D. (2014). Combined effects of perceived politics and psychological capital on job satisfaction, turnover intentions, and performance. Journal of Management, 40(7), 1813-1830.

Atkins, P. W., \& Stough, C. (2005). Does emotional intelligence change with age?.

Aultman, L. P., Williams-Johnson, M. R., \& Schutz, P. A. (2009). Boundary dilemmas in teacher-student relationships: Struggling with "the line". Teaching and Teacher Education, 25, 636-646.

Bandura, A. (1997). Editorial. American Journal of Health Promotion, 12(1), 8-10.

Chan, D. W. (2004). Perceived emotional intelligence and self-efficacy among Chinese secondary school teachers in Hong Kong. Personality and Individual Differences, 36(8), 1781-1795.

Chan, D. W. (2008). Emotional intelligence, self efficacy and coping among chinees prospective and in-service teachers in Hong Kong. Educational Psychology, 28(4), 397-408.

Chase, M. A., Lirgg, C. D., \& Carson, R. L. (2001). Development of the physical education teacher efficacy scale: Evaluation of reliability, concurrent and construct validity. In Cincinnati, $\mathrm{OH}$ : American Association of Health, Physical Education, Recreation, and Dance Conference.

Ciarrochi, J. V., Chan, A. Y., \& Caputi, P. (2000). A critical evaluation of the emotional intelligence construct. Personality and Individual differences, 28(3), 539-561.

Cortese, A.D. (2003). The critical role of higher education in creating a sustainable future, Planning for Higher Education, 15-22.

Dunham, J. (1992). Stress in teaching (2nd ed.). London: Routledge.

Educational Instituations Resources Bank (2007). Higher Education in Pakistan. Retrived August 24, 2010, From http://colleges indiaedu.com/asia/Pakistan/highereducation.html.

Fives, H. (2003). What is teacher efficacy and how does it relate to teachers' knowledge? A theoretical review. In American Educational Research Association Annual Conference, Chicago.

Fredrickson, B. L. (2001). The role of positive emotions in positive psychology: The broaden-and-build theory of positive emotions. American psychologist, 56(3), 218.

Geher, G., Betancourt, K., \& Jewell, O. (2017). The Link between Emotional Intelligence and Creativity. Imagination, Cognition and Personality, 0276236617710029. 
Ghanizadeh, A., \& Moafian, F. (2011). The relationship between Iranian EFL teachers' sense of self-efficacy and their pedagogical success in Language Institutes. Asian EFL Journal, 13(2), 249-272.

Gibbs, C. (2003). Effective teaching: Exercising self-efficacy and thought control of action.

Gibbs, S., \& Powell, B. (2012). Teacher efficacy and pupil behaviour: The structure of teachers' individual and collective beliefs and their relationship with numbers of pupils excluded from school. British Journal of Educational Psychology, 82(4), 564-584.

Gibson, S. \& Demo, M.H. (1984). Teacher efficacy: A construct validation. Journal of educational Psychology, 76(4), 569-582.

Goleman, D. (1995). Emotional intelligence. New York: Bantam Books.

Henson, R. K. (2001). Teacher self-efficacy: Substantive implications and measurement dilemmas.

Ho, I. T., \& Hau, K. T. (2004). Australian and Chinese teacher efficacy: Similarities and differences in personal instruction, discipline, guidance efficacy and beliefs in external determinants. Teaching and Teacher Education, 20(3), 313-323.

Jacobs, S. . Kemp, A \& Mitchell,J. (2008). Emotional intelligence: hidden ingredient

Jennings, P. A., \& Greenberg, M. T. (2009). The prosocial classroom: Teacher social and emotional competence in relation to student and classroom outcomes. Review of educational research, 79(1), 491-525.

Klassen, R. M., Tze, V. M. C., Betts, S. M., \& Gordon, K. A. (2011). Teacher efficacy research 1998-2009: Signs of progress or unfulfilled promise? Educational Psychology Review, 23(1), 21-43.

Knoll, N., Rieckmann, N., \& Schwarzer, R. (2005). Coping as a mediator between personality and stress outcomes: A longitudinal study with cataract surgery patients. European Journal of Personality, 19, 229-247.

Kyriacou, C., \& Sutcliffe, J. (1978). A model of teacher stress. Educational Studies, 4, 16.

Kyriacou, Chris. (2001). Teacher stress: Directions for future research. Educational review 53 (1), 27-35.

Luszczynska, A., \& Schwarzer, R. (2005). Social cognitive theory. Predicting health behaviour, 2, 127-169.

Neubert, M. J., Carlson, D. S., Kacmar, K. M., Roberts, J. A., \& Chonko, L. B. (2009). The virtuous influence of ethical leadership behavior: Evidence from the field. Journal of Business Ethics, 90(2), 157-170.

Mayer, J.D., \& Salovey, P. (1997). What is emotional intelligence? In P. Salovey \& D. Sluyter (Eds.), Emotional development and emotional intelligence (pp. 3-31). New York: Basic Books.

Moafian, F., \& Ghanizadeh, A. (2009). The relationship between Iranian EFL teachers' emotional intelligence and their self-efficacy in Language Institutes. System, 37(4), 708-718.

Moafian, F., \& Ghanizadeh, A. (2010). On the relationship between critical thinking and self-efficacy: A case of EFL teachers in language institutes. Journal of Faculty of Letters and Humanities, 5(16), 77-96. 
Penrose, A., Perry, C., \& Ball, I. (2007). Emotional intelligence and teacher self efficacy: The contribution of teacher status and length of experience. Issues in Educational Research, 17(1), 107-126.

Petrides KV, Furnham A (2006). The role of trait emotional intelligence in a genderspecific model of organizational variables. Journal of Applied Social Psychology., 36: 552-569.

Raja, U., Johns, G. \& Ntalianis, F. (2004). The impact of personality on psychological contracts. Academy of Management Journal, 47(3), 350- 367.

Rastegar, M., \& Memarpour, S. (2009). The relationship between emotional intelligence and self-efficacy among Iranian EFL teachers. System, 37(4), 700-707.

Salovey, P., \& Mayer J.D. (1990). Emotional intelligence. Imagination, Cognition and personality, 9(3), 185-211.

Schunk, D. H., \& Meece, J. L. (2005). Self-efficacy beliefs of adolescents. Information AgePublishing.

Schwarzer, \& Greenglass. (1999). 14. Teacher Burnout from a Theoretical Position Paper. Understanding and preventing teacher burnout: A sourcebook of international research and practice, 238.

Schwarzer, R., \& Jerusalem, M. (1995). Optimistic self-beliefs as a resource factor in coping with stress. In Extreme stress and communities: Impact and intervention (pp. 159-177). Springer Netherlands.

Sutton, R. E., \& Wheatley, K. F. (2003). Teachers' emotions and teaching: A review of the literature and directions for future research. Educational psychology review, 15(4), 327-358.

Torndike, E.L. (1920). Intelligence and its use. Harper's magazins, 140,227-235.

Travers, C.J., \& Cooper, C.L. (1996). Teachers under pressure: Stress in the teaching profession. London: Routledge.

Tufail, M., Gul, A., Shahzad, K., \& Khan, K. (2017). The Impact of Challenge and Hindrance Stressors on Job Satisfaction: Moderating Role of Islamic Work Ethics. Journal of Islamic and Business and management, 7(1).

Van Dick, R., \& Wagner, U. (2001). Stress and strain in teaching: A structural equation approach. British Journal of Educational Psychology, 71, 243-259.

Zia, Y. A., \& Tufal, M. (2011). Comparative Analysis of Organizational Commitment among Faculty Members of Public and Private Sector Universities of KP. Journal of Managerial Sciences, 5(1), 37-52. 